\author{
AN INTERNATIONAL JOURNAL OF ARTS AND HUMANITIES \\ (IJAH) \\ Bahir Dar, Ethiopia \\ Vol. 3 (3), S/No 11, July, 2014:195-212 \\ ISSN: 2225-8590 (Print) ISSN 2227-5452 (Online) \\ DOI: http://dx.doi.org/10.4314/ijah.v3i3.14
}

\title{
METAPHONY AND THE THEORY OF GAPPING IN THE PHONOLOGY OF ELEME
}

\author{
NGULUBE, ISAAC EYI, Ph.D. \\ Department of English Studies, University of Port Harcourt \\ Port Harcourt, Rivers State, Nigeria \\ E-mail: isaaceyingulube@yahoo.com \\ Mobile: +2348075220804
}

\begin{abstract}
This paper examines phonologically motivated gaps in the phonology of Eleme. The author follows Rice (2005), which 'uses an approach to modeling gaps based on a tension between markedness constraints, faithfulness constraints and constraints which require the expression of morphological categories'. The author explores specifically vowel harmony in Eleme, arguing that the language has gaps in its phonological systems. The approach predicts that the same phonotactics problem may be solved by a repair in one phonological context and by a gap in another. This prediction is illustrated and further implications are explored.
\end{abstract}

\section{Introduction}

The term vowel harmony is used in two disparate senses. In the first sense, it refers to any type of long-distance assimilatory process of vowels, either progressive or regressive. If employed in this sense, the term vowel harmony is synonymous with the term metaphony. In the second sense, vowel harmony refers only to progressive 
vowel harmony (from start-to-finish). For regressive harmony, the term umlaut is used. In this sense, metaphony is the general term while vowel harmony and umlaut are both sub types of metaphony. The term umlaut is also used in a different sense to refer to a type of vowel gradation (Regan et al. 1999; Jacobson 1978). This article will use amity has proposed by Ngulube (2013) for both progressive and regressive harmony. The term amity accurately represents the relationship that is envisaged here. Besides, it incorporates notions such as concord, agreement and harmony.

\section{Gapping}

Gapping has been extensively discussed by scholars over the years. Sophie Repp (2009, p. xi-266) examined 'gapping and its interaction with negation'. Repp presents a lucidly argued novel analysis of gapping from the syntactic perspective. The work equally contains 'thoughtful, in-depth treatments of the syntax and semantics of polarity, denials, and negation'. Repp argues that gapping is 'widely addressed in the ellipsis literature', but 'persistently resists a unified analysis with other, better-understood types of ellipsis, such as sluicing.' She posits 'gapping, which occurs only in coordinated matrix clauses, targets, under identify with ANTECEDENT in the first conjunction $\left(\mathrm{C}_{1}\right)$, the finite verb/auxiliary and optionally, additional material (together, the GAP) in the second conjunction $\left(\mathrm{C}_{2}\right)$.'

Repp further argues that ' $\mathrm{C}_{2}$ contains at least two REMNANTS, each consisting of phonologically represented material that contrasts with a CORRELATE IN $\mathrm{C}_{1}$.' Repp's position is that 'the gaps complement can be a remnant, which initially suggests that gapping can - atypically for - target a non-constituent.' Many treatments of gapping, including Repp's, argue that this non-constituency is only apparent, as is the 'ellipsis' itself (if narrowly defined as 'deletion' at the P (honological) $\mathrm{F}$ (orm)).

A further oddity of gapping - and the main empirical puzzle Repp investigates involves its interaction with negation, which yields three different scopal readings, and which Repp argues implicates a non-unified analysis of gapping. She proffered the following examples:

1 (a) Distributed Scope $((-\mathrm{A} \Lambda(-\mathrm{B}))$,

Max didn't read the book and Martha the magazine.

[Max didn't read the book] and [Martha didn't read the magazine.]

(b). Narrow scope $((-A) \wedge B)$,

Pete wasn't called by Vanessa but John by Jessie. 
[Pete wasn't called by Vanessa] but [John was called by Jessie.]

(c) Wide scope $(-(\mathrm{A} \wedge \mathrm{B}))$,

Kim didn't play bingo and Sandy sat at home all night.

It is not the case that [Kim played bingo and Sandy sat at home all night]

Repp seeks to fill a gap (in another sense) in the literature: no previous proposal successfully accounts for all three readings. Of the three major families of gapping analyses - small conjunct coordination accounts, deletion and copying accounts, and three - dimensional/sharing accounts. Repp's analysis is most closely aligned with small conjunct coordination accounts.

Johnson (1996, 2003) and Winkler (2005) are primarily concerned with accounting for wide scope. Repp proposes that the derivation of wide readings indeed involves 'small' conjuncts, but departs from earlier analyses in identifying as Topic phrase (TopPs in Rizzi's 1997 left-peripheral architecture), and in claiming that distributed/narrow scope readings instead involve large conjuncts, viz Force phrases. To yield narrow scope, $\mathrm{C}_{2}$ contains a null 'positive' (polarity) morpheme, which contrasts with the overt negative morpheme in $\mathrm{C}_{1}$, under distributed scope; both conjuncts contain negation (Fortin 2010, p. 241).

Fortin (2010, p. 242) further points out that Repp's analyses reveal that two kinds of negation are seen in gapping. Propositional negation is found with distributive scope and contrastive narrow scope. Illocutionary negation or negation at the level of the speech act is operative with wide scope and corrective narrow scope: both are denials, 'a speech act that objects to a previous utterance' (151). Both Repp and Fortin agree that propositional and illocutionary negations are syntactically distinct, the key to Repp's demonstration that wide scope involves TopPs: illocutionary negation takes a very high position, scoping over both conjuncts. This is further supported by wide intonation, which is a single intonational phrase.

Repp further proposes that all gapping involves an L (ogical) F (orm) - copying mechanism (Chung, Ludusaw and McClosekey 1995), which she interprets as sideways movement (Nunes, 2004) from $\mathrm{C} 1$ to $\mathrm{C} 2$, following transfer of $\mathrm{C} 1$ to PF.

Finally, Fortin (2010, pp. 242-243) states that a semantic/pragmatic principle, the PRINCIPLE OF BALANCED CONTRAST (PBC), must be satisfied for gapping to succeed: 'both conjuncts must make the same kind of contribution to a common discourse topic' (83). 
It is clear from this review of literature that a lot has been done on gapping at the syntactic level, but not much has been done at the phonological level. This provides the necessary justification for this paper.

\section{Vowel amity}

According to Lloret (2007) phonological rule in certain languages require that the vowels of a word all share a specified feature such as vowel height [HIGH, MID, LOW]; vowel backness [FRONT, CENTRAL, BACK]; vowel roundedness [ROUNDED, UNROUNDED]; tongue root position [ADVANCED, RETRACTED $= \pm \mathrm{ATR}$ ]; and nasalization [ORAL, NASAL = in this case, a nasal consonant is usually the trigger], thereby conditioning the form that affixes may take. Smith (2007) posits 'vowel harmony is a type of long-distance assimilatory phonological process involving vowels that occur in some languages.' Crystal (2009, pp. 224-225) elucidates vowel harmony as 'a term used in phonology to refer to the way the articulation of one phonological unit is influenced by (is in harmony with) another unit in the same word or phrase.'

These three linguists are agreed that harmony processes are 'long-distance' in the sense that the assimilation involves sounds that are separated by intervening segments (usually consonants). In essence, harmony refers to the assimilation of sounds that are not adjacent to each other. For instance, a vowel at the beginning of a word can trigger assimilation in a vowel at the end of a word. The assimilation occurs across the entire word in most languages. The vowel that causes the vowel assimilation is called the trigger while the vowels that assimilate (or harmonize) are termed targets. When the vowel triggers lie within the root or stem of a word and the affixes contains the targets, this is called stem-controlled vowel harmony. The opposite situation is called dominant (Kramer 2003; Li 1996).

In African languages, vowels can be said to belong to particular sets or classes, such as back vowels or rounded vowels. Some languages are reported to have more than one system of harmony. For instance, Eleme has a rounding harmony superimposed over a backness harmony. Within languages with vowel harmony, not all vowels need participate in the vowel conversions; these vowels are termed neutral. Neutral may be opaque and block harmonic processes or they may be transparent and not affect them. Intervening consonants are also often transparent (Regan et al. 1999). It is observed that languages with vowel harmony permit 'lexical disharmony' or words with mixed sets of vowels even when an opaque neutral vowel is involved. van der Hulst and van de Weijer (1995, p. 496) point to two such situations: polysyllabic trigger morphemes may contain non-neutral vowels from opposite harmonic sets and certain target morphemes simply fail to harmonize. 
The discussion here is centered on the phenomenon of vowel amity in Eleme and it is divided into three parts. The first part is a sketch of the synchronic status of the vowel harmony situations in a number of languages of the Niger-Congo family. The second part focuses on the synchronic status of vowel harmony in Eleme. The third part is a discussion on which morphemes participate in harmony and which do not.

Vowel amity (or harmony) is a captivating subject, which might help to explain the complexion of phonological delineations since it operates partially as a segmental and to a degree as a suprasegmental property (Katamba 1989, p. 212).

\section{Vowel harmony in some Niger-Congo languages}

Many types of co-occurrence patterns have been attested in the synchronic forms of a number of languages of the Niger-Congo family. Abua, a language spoken in the Rivers State of Nigeria, has ten distinctive vowel phonemes, which divides into two harmony sets (Woodman 1985).

\section{Set $A$ : i e o u a}

Set $B$ : I $\varepsilon$ ○ व

Ebira, spoken in Kwara State of Nigeria, has nine vowels (Adive 1986). The nine vowels operate in two harmony sets. The vowel $\mathbf{a}$ is common to both sets.

Set $A$ : i e o u a

Set $B:$ I $\varepsilon \supset$ ○ a

Egene, spoken in the Rivers State of Nigeria, has full vowel harmony that does not break down because of its ten-vowel system (Ngulube 2011, p. 27).

\begin{tabular}{|c|c|c|c|c|}
\hline \multicolumn{3}{|c|}{ PLAIN } & \multicolumn{2}{|c|}{ SUB DOTS } \\
\hline \multicolumn{3}{|c|}{ FRONT BACK } & & BACK \\
\hline CLOSE & $\mathrm{i}$ & $\mathrm{u}$ & $\mathrm{i}$ & $\mathrm{u}$ \\
\hline MID & $\mathrm{e}$ & o & $\mathrm{e}$ & o \\
\hline OPEN & $\mathrm{a}$ & & & \\
\hline
\end{tabular}

Williamson (1966, p. 67) suggests that Central Igbo spoken around Owerri has eight vowels, which divides into two harmony sets.

Set $A$ : i e o u

Set B: г а $\supset$ v 
Ndimele (2011, p. 1) reports that Echie has eight vowels, which divides into two harmony sets, wide and narrow, such that it is rare to find vowels from the two sets occurring together.

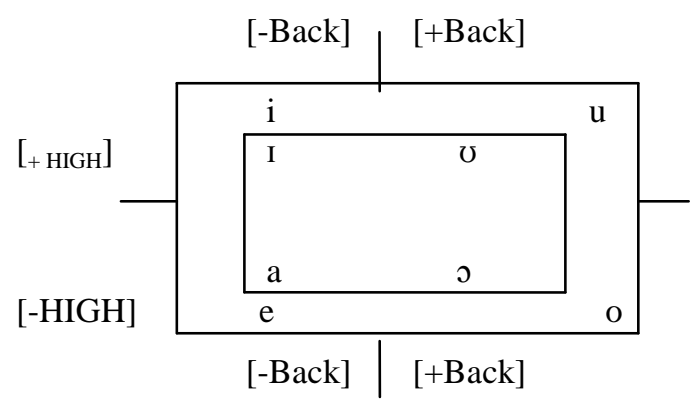

Ngulube (2011, p. 39) states that Egbema has eight vowels but these vowels cannot be divided into two sets of four each; where the vowels from one set cannot co-occur with those from the other set in simple words. This is because the eight phonemic vowels of Egbema derive from five basic vowels. There are five short oral plain vowels and three short dotted vowels in Egbema. If the \pm ATR contrast is suspended the language clearly have five basic vowels.

\section{FRONT BACK}

$\begin{array}{lllll}\text { CLOSE } & \text { i } & \text { I } & \text { u } & \text { u } \\ \text { MID } & \text { e } & & \text { o } & \text { o }\end{array}$

OPEN (a)

The open front vowel $(\boldsymbol{a})$ is in parenthesis because it appears to be neutral; operating either as SET 1 or SET 2. Ngulube did not report similar behaviour with [e], which occurs solely with SET 1 vowels as in ife 'things'. Ndoni has a system of eight vowels consisting of three narrow vowels and five wide vowels (Ngulube 2011, p. 88).

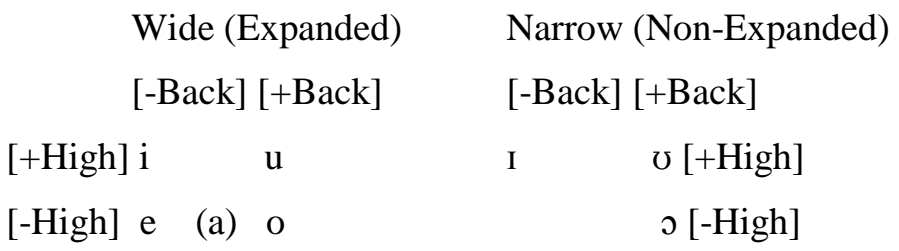

Okrika has nine-vowel system divided into two sets as represented below. 


\begin{tabular}{|c|c|c|}
\hline \multirow{2}{*}{\multicolumn{2}{|c|}{$\begin{array}{l}\text { Wide (Expanded) } \\
\text { [-Back] [+Back] }\end{array}$}} & Narrow (Non-Expanded) \\
\hline & & [-Back] [+Back] \\
\hline [+High] & $\mathrm{u}$ & $\mho[+$ High $]$ \\
\hline [-High] & o & o [-High] \\
\hline
\end{tabular}

Isaac (2011, p. 63) reports that Gokana has seven oral vowels which function in two partial sets, as follows:

\section{SET 1: i e a o u \\ SET 2: ị ẹ ạ ọ}

Ngulube (2011, p. 49) claims that Ekpeye has nine distinctive vowel phonemes. The nine vowels divided into two harmonious sets.

SET 1

FRONT BACK

$\begin{array}{lccccc} & \text { i } & \text { u } & \text { i } & \text { u } \\ \text { DOMINANT } & \text { e } & \text { o } & \text { e } & \text { o } \\ \text { NEUTRAL } & \text { a } & & & & \end{array}$

\section{SET 2}

\section{FRONT BACK}

Fombo $(1975$, p. 3) suggests that Ibani has two sets of vowels, which he designates 'heavy' and 'light'.

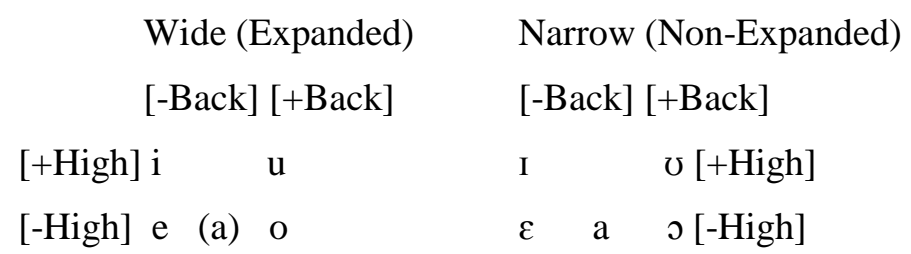

The vowel (a) is neutral, it can occur with any set. In Yoruba, a major Nigeria language, the co-occurrence pattern for instance differs from that of Igbo presented above in that Yoruba exhibits partial vowel harmony. Akinkugbe (1978) observes that Standard Yoruba has seven oral /i e $\varepsilon$ a o $\supset$ u/ and three nasalized vowels / $\tilde{\mathrm{u}} \mathrm{u} /$ /. These vowels form two harmony sets.

$$
\text { Set } A \quad \text { Set } B
$$




$\begin{array}{lcll}\mathrm{i} \tilde{\mathrm{I}} & \mathrm{u} \tilde{\mathrm{u}} & \mathrm{i} \tilde{\mathrm{I}} & \mathrm{u} \tilde{\mathrm{u}} \\ \mathrm{e} & \mathrm{o} & \varepsilon(\tilde{\varepsilon}) & \jmath(\tilde{\mathrm{o}}) \\ \mathrm{a} \tilde{\mathrm{a}} & & \mathrm{a}(\tilde{\mathrm{a}}) & \end{array}$

In the Yoruba data only e o, on the one hand, and $\varepsilon \rho$, on the other, strictly belong to two different sets and do not co-occur. The vowels i u and a can co-occur with e, o or $\varepsilon$. The co-occurrence of the vowel $a$ with $e$ and $o$ is also partially restricted. I now present the analysis.

\section{Status of vowel amity in Eleme}

According to Faraclas (1989, p. 388) 'only relics of the original [Proto-BenueCongo ten-vowel] harmony system have survived in Ogoni', and Ikoro (1996, p. 25) confirms that 'there is no indication of any kind of vowel harmony operating in Kana'. But Hyman (1983, p. 174) asserts that vowel harmony is evident in Gokana and Nwolu-Obele (1998, p. 135) claims that vowel harmony has momentous weight over phonetic realization of individual segments in Eleme. He contends that Eleme vowels divide into two harmonic sets: 'e and related sounds' and ' $\varepsilon$ and related sounds'. He calls the close-mid set 'wide throat' and the open-mid set 'narrow throat' sounds. This is compatible with an [ \pm ATR] analysis. ${ }^{1}$ The assertions of Hyman and Nwolu-Obele contrast with that of Faraclas and Ikoro, who imply that vowel harmony is not common elsewhere in Ogonoid, Bond (2006, p. 63) asserts that 'Eleme is characterized by a system of vowel harmony in which the vowel quality of verbal affixes is conditioned by the qualities of adjacent vowels in the stem'. Henceforth I present my data, analysis and discussion.

First, my data indicates that in Eleme vowel harmony is an active synchronic process. Secondly, the domain of vowel harmony is no longer than the word; very often it is between the affixes and the adjacent vowels in the stem. This suggests that vowel harmony applies across morpheme boundaries, as the quality of nominal or verbal affix is conditioned by the quality of the adjacent vowel in the stem. But, vowel harmony does not spread across word boundaries, as (Ex.l) below indicates. Consequently, harmony may be used as criteria both for boundedness and delimiting prosodic words in Eleme (Nespor and Vogel 1986). To substantiate these claims detailed analysis and discussions are presented henceforth. The vowel harmony sets in Eleme are summarized on Table 1 below.

Ex.1

${ }^{1}$ See Clements (2000, p.135-8) for discussion of the suitability of the use of $[ \pm \mathrm{ART}]$ in language descriptions. 
a. ànè bó-ē

3SG treat: PT $\varnothing 3 \mathrm{SG}$

He treated it. b. à?ó ló- $\bar{\varepsilon}$

2SG remove: PT - $\varnothing 3$ SG

You (SG) removed it.

In Ex.la, It is obvious that the third person singular object suffix -e harmonizes with verb root bo 'treat'. Similarly, in Ex.1b where the verb root changes to lo 'remove', the third person singular object suffix changes to $-\varepsilon$ to harmonize with the verb root. Note here that the third person singular subject prefix ànè and the second person singular subject prefix à?ó are not drawn into harmonizing with their respective verb roots. This shows clearly that vowel harmony does not operate across word boundary.

Table 1: Eleme vowel amity sets

\begin{tabular}{|c|c|c|c|c|}
\hline \multirow[b]{3}{*}{ AMITY SET } & \multicolumn{2}{|c|}{ Close-mid set } & \multicolumn{2}{|c|}{ Open-mid set } \\
\hline & FRONT & BACK & FRONT & BACK \\
\hline & $\mathrm{e}$ & o & $\tilde{\varepsilon}$ & 0 \\
\hline NEUTRAL SET & i I & $\mathrm{u} \tilde{\mathrm{u}}$ & $\mathrm{a}$ & \\
\hline
\end{tabular}

\begin{tabular}{|c|c|c|c|}
\hline \multirow[t]{3}{*}{$(E x .2)$} & èbó head & \multicolumn{2}{|l|}{ Èbó bundle } \\
\hline & Òbé a name & ògẽ̀ knife & ùríí creel \\
\hline & è?ó bush & غ̀s s̃̀ song & àrú death \\
\hline \multirow[t]{3}{*}{$(E x .2 i i i)$} & ètfíí market & (Ex.2iv) dżĩ் extinguish & \\
\hline & òkũ basket & jtaa three & \\
\hline & kèsã wake up & kùre gather together & \\
\hline
\end{tabular}

In examples $(E x .2)-(E x .2 i v)$ above, $(E x .2)$ show the [+ATR] vowels co-occurring, (Ex.2i) show [-ATR] vowels co-occurring, (Ex.2ii) show the neutral set co-occurring while (Ex.2iii) and (Ex.2iv) show the neutral set co-occurring with the [ \pm ART] sets.

Table 1 above shows that Eleme vowels fall into two harmonic sets each

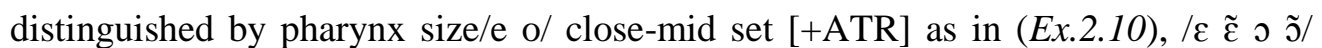
open-mid set [-ATR] as in (Ex.2i) and /I ĩ a ã u ũ/ are neutral as in (Ex.2ii). The 
close-mid set vowels combine with the neutral high vowels /i $\tilde{1} \mathrm{u}$ ũ/ as in (Ex.2iii) while the open-mid set vowels combine with the low vowels /a ã/ as in (Ex.2iv). Verb roots with CV syllables may have any of the set or neutral vowel as their nucleus. Certain verb roots with CVCV structures do not permit vowels pertaining to both close and open-mid sets co-occurring in the same word. Note that, a verb such as bere 'lean' follow the rule, a conjectural item like *bere is not allowed given that the vowels are not harmonic. The same limitation is not observed with neutral vowels. Other verb roots with CVCV structures may permit a vowel pertaining to one set and a neutral vowel pertaining to the opposite set, as in bela 'like'. Furthermore, some nouns with V-CV-V structures may also allow two neutral vowels as in ùríi 'creel'.

\section{Participant and non-participant morphemes}

Table 2 below contains three sub-tables titled subject prefix, subject suffix and object suffix. These sub-tables sub-divide into singular and plural participant and/or non-participant morphemes. It is further sub-divided into first, second and third persons. The purpose of this table is to show at a glance which morpheme participates in Eleme vowel harmony and which do not.

Table 2: Participant and non-participant Morphemes in Eleme vowel harmony

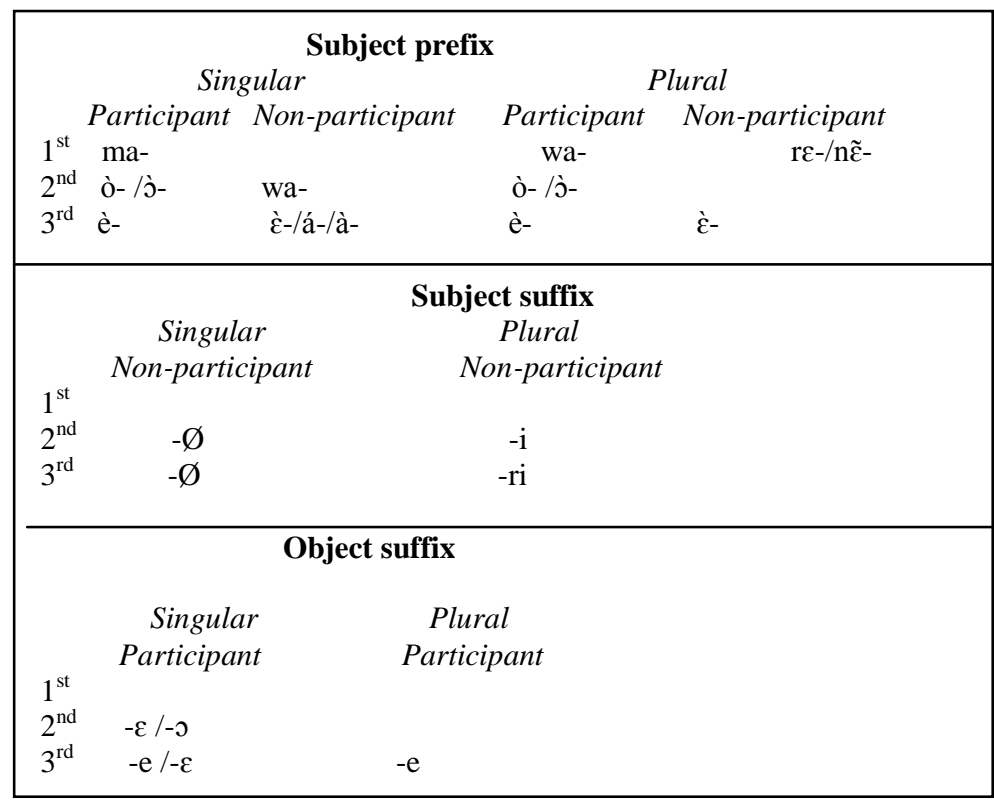


The discussion here focuses first on the subject prefix in harmony with the vowel of the root. Secondly, neutral vowel intervening between a subject prefix and a root harmonizes with the prefix. Thirdly, subject suffix not participating in harmony and finally the object suffix harmonizes with the vowel of the interposing suffix.

While the first person singular and plural subject prefixes ma- and wa-respectively harmonizes with the vowel of the verb root ?à 'leave' as in $(E x .3 a)$ below, the first person plural subject prefixes $r \varepsilon$ - and n $\tilde{\varepsilon}$ do not participate in harmony as in $(E x .3 b)$ below.

Ex.3
a. mã-?à
nẽwa-?à

1SGPT-leave

1PL PL-leave

I left.

We left.

b. re-Perá

ne-fo-a dzá

1PL-stop

1PL- farm HAB. food

We stopped. We farm food.

The second person singular and plural subject prefix ò- harmonizes with the vowel of the verb root as in $(E x .4 a$ and $b)$ below. The second person singular subject prefix $\dot{j}$ - also participates in vowel harmony as in $(E x .4 c)$ but the third person singular and/or plural subject prefix $\grave{\varepsilon}$ - does not as in $(E x .4 d)$.

Ex.4
a. ò-Perá- $\varnothing$
b. ò-Perá-i
2- stop- SG
2-stop-2PL
You (sg) stopped.
You (pl) stopped.

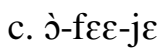
d. $\varepsilon$-kpoo-j $\varepsilon$
2 SG kill-him
3 SG drive-him

You (sg) killed him. We drove him (away).

The third person singular and plural subject prefix e- also harmonizes with the vowel of the verb root as in (Ex.5) below.
Ex.5
a. è-Perá- $\varnothing$
b. è-Perá-ri
3- stop- SG
3-stop-3PL 


\section{He stopped. They stopped.}

In certain $\mathrm{CV}$ verb roots, third person subject prefix harmonizes with the vowel of the root. This is exemplified in (Ex. 6) below where the third person singular subject prefix takes the form e- with monosyllabic verb roots containing a close-mid set vowel as in $(E x .6 a)$, while it takes the form $\varepsilon$-with roots containing an open-mid set vowel as in $(E x .6 b)$. This is an evidence of systematic synchronic alternations.

Ex.6

$\begin{array}{llrl}\text { a. è-dé } & \text { He ate. } & \text { b. } \varepsilon \text {-n } \varepsilon & \text { He passed (faeces). } \\ \text { è-dzu } & \text { He survived. } & \varepsilon \text {-d } \varepsilon & \text { He moulded. } \\ \text { è-si } & \text { He went. } & \varepsilon \text {-?ว } & \text { He roasted. } \\ \text { è-pi } & \text { He bit. } & \varepsilon \text {-t̃̃ } & \text { He poured. } \\ \text { è-bo } & \text { He got up. } & \varepsilon \text {-da } & \text { He licked. } \\ \text { è-Pu } & \text { He died. } & \varepsilon \text {-tã } & \text { He shot. }\end{array}$

It is observed that Eleme verbs realized with neutral vowels /i/ or /a/ as nucleus do not harmonize with the amity set (close-mid or open-mid) vowels. What happens is that while the neutral vowels do not harmonize with both amity sets (close-mid or open-mid) of vowels, the amity sets (close-mid or open-mid) of vowels harmonize with stems having neutral vowels pertaining to the same set. I shall therefore discuss only affixes possessing amity set (close-mid or open-mid) of vowels here.

Occasionally a neutral vowel prefix occurs between a subject prefix and a verb root, the subject prefix harmonizes with the vowel of the prefix. This harmony system is exemplified with close-mid set vowels in $(E x .7 a)$ whereas $(E x .7 b)$ illustrates the open-mid set equivalent. In $(E x .7 a)$, $\grave{\varepsilon}$ - harmonizes with the intervening ka not the verb root bo 'treat'. Similarly, in $(E x .7 b)$, e- harmonizes with ki not the verb root ?o 'roast'. What is expected is for $\varepsilon$ - and e- to harmonize with their respective verb roots but that is not the case here. Therefore, it is suggested that the subject prefix harmonizes with the vowel of the prefix.

Ex.7

a. è-ki bó-e غ̀-ka bo-e

\section{3-PROX treat 03SG 3-CONT. treat 03SG}

He is about to treat it. He is treating it.

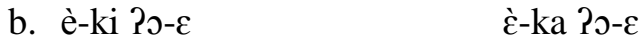

3-PROX roast 03SG 3-CONT. roast 03SG 
He is about to roast it. He is roasting it.

In contrast to the examples in $(E x .7 b)$, when a suffix containing a neutral vowel occurs closer to the root than the object suffix, the object suffix harmonizes with the vowel of the intervening suffix. This is illustrated with a verb root with a close-mid set vowel in $(E x .8 a)$ and with a verb root with an open-mid set vowel in $(E x .8 b)$. In $(E x .8 b)$, it is expected that the third person singular object suffix -e will harmonize with the verb root 20 'roast' but what happens is -e harmonizes instead with the intervening suffix -ri-. This is evidence that the object suffix harmonizes with the vowel of the intervening suffix.
$($ Ex.8)
a. è-bo ri-e
b. $\varepsilon$-?o ri-e
3-tie-3PL-0SG
3-tie-3PL 03SG
They treated it.
They roasted it.

With regards to the subject suffixes, the second and third person singular subject suffixes $-\varnothing$ and the second and third person plural subject suffixes $-\mathrm{i}$ and ri do not participate in vowel harmony as in (Ex.9 and Ex.10) below. The data and discussion so far bear out my position as outlined above.
(Ex.9)
(Ex.10)
a. è-?erá- $\varnothing$
b. ò-Perá-i
a. . è-Perá- $\varnothing \quad$ b. è-Perá-ri
2- stop- SG
2-stop-2PL
3- stop- SG
3-stop-3PL

You (sg) stopped. You (pl) stopped. He stopped. They stopped.

The examples in (Ex.11) below are provided to illustrate that harmony also prevails between roots and object suffix. In (Ex.11), the third person singular object suffix has the form -e with $\mathrm{CV}$ verb roots containing close-mid set vowels; while in (Ex.12), the form $-\varepsilon$ occurs with comparable roots containing open-mid set vowels. Note that the third person object suffixes in these examples are harmonic with the vowels of the verb roots.
Ex.11
a. ane be-e
b. ane bo-e
3SG fight: PT ø3SG
3SG treat: PT $\varnothing 3 S G$
He fought it.
He treated it.

\section{Ex.12}



a. aje $n \tilde{\varepsilon}-\tilde{\varepsilon}$
b. aje ?ว-ع
3SG give $\mathrm{O} 3 \mathrm{SG}$
$3 \mathrm{SG}$ roast $\mathrm{O} 3 \mathrm{SG}$
He gave it.
He roasted it.

In Eleme verbs take pronominal prefixes from vowels of the same set as the verb root, compare o-do 'you shared' versus o-do 'you fell'. Within nouns, there is a kind of vowel harmony whereby both noun stem and prefix vowel are drawn from the same set, compare o-be 'fight' and e-?っ 'bush' versus $0-? \tilde{\varepsilon}$ 'moon' and $\varepsilon$-? The above data and discussions indicate that in Eleme vowel harmony is an active synchronic process.

\section{Analyses}

Abua, Echie, Egene and Owerri Igbo vowel harmony systems permit no gaps. Linguists working in these languages support the argument that gaps do not exist in the vowel harmony of these languages. In contrast, Ebira, Egbema, Ekpeye, Ibani, Gokana, Ndoni and Okrika vowel harmony systems, the gaps in the vowel harmony systems are apparent. In certain cases the open central vowel [a] is not common to both sets creating a gap. Linguists working in these languages argue that gap is inevitable. These languages use different repair strategies to avoid gaps. One of such repair efforts is postulating a neutral [a] which occurs in both sets. A good example of the repair efforts in some languages is that embark upon by the Yoruba language as exemplified above. This ensures that the language exhibits no gap. Ebira bridges its gap by replicating the low central vowel [a]. The vowel [a] is common to both sets. The open central vowel [a] originally belongs to set 1 but is loan by the set 2 vowels as a repair strategy to bridge the existing gap in the system. Most systems favour binary choices.

Underlyingly, all vowel harmony systems exhibit gaps but different languages use different repair strategies to bridge the gaps. On the other hand, a number of languages leave the gaps because in their present form they have reduced the earlier historical ten-vowel system of their proto-languages to numbers ranging from nine to seven or less (Yul-Ifode 1995, p. 55).

Finally, vowel harmony is presented autosegmentally using three parameters: 'Identify the set of harmonizing features, which are suprasegmentalised and placed on a separate tier; identify the class elements (vowels), which bear the harmonizing features; identify the set of opaque segments. Opaque segments are vowels, which ought to obey the vowel harmony rules but fail to do so because they are specified in the lexicon for the harmonizing feature and are therefore exempt from vowel harmony rules which fill in blanks for the harmonizing feature during a derivation; 
mutatis mutandis, harmonizing features are associated with vowels in accordance with the requirements of well formedness conditions' (Katamba 1989: 212).

The difference between Vowel harmony and harmonizing features on one hand and tone and stress on the other is sum up here: 'Vowel harmony differs in a significant way from archetypal suprasegmental properties like tones and stress. While these are always located on a separate tier from that where vowels and consonants are found, harmonizing phonological features like [back], [round], [high] and [ATR] are normally part of the segmental representation of individual vowels. But they are extracted from the segmental tier and are placed on a distinct harmony tier and cease functioning as properties of individual segments. But when vowel harmony occurs, they are extracted from the segmental tier and cease to function as properties of individual segments: they spread to all vowels within a specified domain. This domain is usually the word.' (Katamba 1989: 211)

In the examples below the principles listed above are deployed to link the feature [ATR] in other to derive the Eleme forms. I now present the illustration of vowel harmony below. The upper case letters are employed in the URs for the target vowels following Katamba (1989: 213).

$$
\text { UR SF }
$$

$$
\begin{aligned}
& \text { Vowel harmony row [+ATR] } \\
& \text { Segmental row Ets I I } \rightarrow \text { [ètfii] market } \\
& \text { Vowel harmony row [+ATR] } \\
& \text { Segmental row Et OG I } \rightarrow \text { [etogi] He carves. } \\
& \text { Vowel harmony row [+ATR] } \\
& \text { Segmental row } \mathrm{Eb} \text { OO } \mathrm{nE} \rightarrow[\varepsilon b \supset 0 n \varepsilon] \text { He gathers. }
\end{aligned}
$$

It is worth mentioning that the modus operandi deployed here is not the only possible and/or available technique of studying vowel quality. There are three other approaches: the 'overall spectral shape', 'dynamic specification' and the 'silent centre'. The first of these is associated with Bladon and Lindblom (1981). Their paper measures the 'perceptual distance between vowels' by appraising 'the degree of overlap of their auditory spectra'. Harris (1994) also investigating this idea suggests three elements 'I, A and U', these are expounded in terms of 'spectral shape templates'. I stand for conspicuous docking at both 'high and low 
frequencies'. U slope downwards towards the right at 'low frequencies' and A peaks in the centre. The second, dynamic specification (Strange1989a, 1989b) focuses on the dynamism that characterizes vowels, such as 'formant trajectories in CVC syllables'. In the third perspicacity of the 'silent centre' listeners are requested 'to identify syllables' that lack nucleus. The listeners were able to tell correctly what the vowel is; this affirms that 'dynamic as well as static information about spectral structure' is used as cues. The one thing common to all three approaches is that they concentrate on the 'steady state of the spoken vowel' (Hayward 2000, p.146).

Finally, the discussion ends with vowel harmony, where the harmonic constraints on vocalic quality of verbal suffixes were exemplified.

\section{References}

Adive, J.R. 1986. Ebira orthography In: Orthographies of Nigerian languages manual IV. R.G. Armstrong ed. National Language Center, Federal ministry of education, Lagos.

Akinkugbe, Olufemi Odutayo. 1978. A comparative phonology of Yoruba dialects, Isekeri and Igala. PhD thesis: University of Ibadan.

Bond, Oliver. 2006. Aspects of Eleme verbal morphosyntax. PhD thesis: University of Manchester.

Chung, Sandra, William Ladusaw \& James McCloskey. 1995. Sluicing and logical form. Natural Language Semantics 3.3, 239-82.

Crystal, David. 2009. The future of English. Wales University Press.

Faraclas, N.G. 1989. Cross River in John Bendor-Samuel (eds.), The Niger-Congo Languages, Pp. 377 - 399. Lanham.

Fombo, Adadonye. 1975. Ibani Bibi Dawo Diri. Occasional Publication No. 2 Rivers Readers Project

Fortin, Catherine. 2011. 'Review of negation in gapping'. In Journal of Linguistics 47. Cambridge University Press

Hyman, Larry M. 1983. Are there syllables in Gokana? In Current approaches to African Linguistics 2, 171-179 eds. Jonathan Kaye, D. Sportiche and A. Dugas [Publications in African Languages and Linguistics 5] Dordrecht: Fortis.

Ikoro, Suanu M. 1996. The Kana language. Leiden: CNWS Publications. 
Isaac Baridisi Hope. 2011. Kana Orthography in Orthographies of Nigerian Languages Manual IX Ozo-mekuri Ndimele (ed.) Nigerian Educational Research \& Development Council.

Johnson, Kyle. 1996/2003. In search of the English middle field. Ms.. University of Massachusetts at Amherst.

Regan, O. Catherine and Orvokki Heinamaki.(1999) 'Variant in Finnish vowel harmony: An OT account' in National Language \& Linguistic Theory Vol. 17, No. 2. Doi: 10. 1023/ A: 1006158818498.

Repp, Sophie. 2011. Negation in gapping (Oxford Studies in Theoretical Linguistics 22). Oxford: Oxford University Press, 2009. Pp. xi-266.

Rice, Curt. 2005. 'Nothing is a phonological fact: Gaps and repairs at the phonology-morphology interface. PhD thesis: Castel University of Tromso.

Rizzi, Luigi. 1997. The fine structure of the left periphery. In Liliane Haegeman (ed.), Elements of grammar: Handbook of generative syntax, 281-337. Kluwer: Dordrecht.

Smith, Eric J. M. (2007). 'Harmony and the vowel inventory of Sumerian.' Journal of Cuneiform studies 57.

Jacobson, Leo Carl. (1978). Dholuo vowel harmony: A phonetic investigation. Los Angeles: University of California.

Katamba, Francis. 1989. An introduction to phonology. Longman Group Limited, Uk.

Kramer, Martin. (2003). Vowel harmony and correspondence theory. Berlin: Mouton de Gruter.

Li, Bing. (1996). Tungusic vowel harmony: A description and analysis. The Hague: Holland Academic Graphics.

Lloret, Maria-Rosa. 2007. 'On the nature of vowel harmony: Spreading with a purpose' in Bisetto, Antonietta, Barbieri, Francesco, Proceedings of the XXXIII Incontro di Grammatica Genetira, pp. 15-35.

Ndimele, Ozo-mekuri 2011. Echie Orthography in Orthographies of Nigerian Languages Manual IX Nigerian Educational Research \& Development Council.

Nespor, Marina and Vogel, Irene. 1986. Prosodic phonology. Dordrecht: Foris. 62:56-119. 
Ngulube, Isaac Eyi. 2013. The Eleme phonology. The Linguistic Association of Nigeria (LAN) in Collaboration with M\&J Orbit Communications Ltd. Port Harcourt, Nigeria.

Ngulube, Isaac Eyi. 2011. Egene Orthography in Orthographies of Nigerian Languages Manual IX Ozo-mekuri Ndimele (ed.) Nigerian Educational Research \& Development Council.

Ngulube, Isaac Eyi. 2011. Ekpeye Orthography in Orthographies of Nigerian Languages Manual IX Ozo-mekuri Ndimele (ed.) Nigerian Educational Research \& Development Council.

Ngulube, Isaac Eyi. 2011. Egbema Orthography in Orthographies of Nigerian Languages Manual IX Ozo-mekuri Ndimele (ed.) Nigerian Educational Research \& Development Council.

Nwolu-Obele, Dada. 1998. Foundation Studies in Eleme. Outreach Publication. Port Harcourt, Nigeria.

Nunes, Jairo. 2004. Linearization of chains and sideward movement. Cambridge, MA: MIT Press.

Van der Hulst, H. and van der Weijer. 1995. Word prosodic systems in the languages of Europe. Berlin: Mouton de Gruyter.

Winkler, Susanne. 2005. Ellispsis and focus in generative grammar. Berlin: Mouton de Gruyter.

Woodman, E.A.K. 1985. Affixation in Abua. B.A Long essay: University of Port Harcourt, Nigeria.

Williamson, Kay. 1966. The status of /e/ in Onitsha Igbo. In the Journal of West African languages 3, 2 pp 67 - 69 